\title{
A COMPUTER FILE OF NEW ZEALAND EARTHQUAKES
}

\author{
W.D.Smith*
}

The Seismological Observatory, Wellington, is often asked to supply lists of earthquakes that have occurred in particular geographical areas of New Zealand, near certain towns or planned construction sites, or chosen on other criteria. In the past the preparation of such a list has necessitated a time-consuming examination of the printed Bulletins and other less accessible records. This procedure has now been greatly simplified by the preparation of a master file of earthquakes known to have occurred in the New zealand region. This file contains over 13,000 earthquake origins and is stored on magnetic tape for use on the Burroughs B6700 computer at the Victoria University of Wellington.

Each computer listing commences with a description of the data presented for each earthquake. These data are as follows:

1. Date and time of occurrence.

2. Serial number assigned by the observatory in the published Bulletins.

3. Latitude, longitude and focal depth.

4. Magnitude.

5. Parameters indicating the precision with which the earthquake was located.

6. A code identifying the procedure by which the epicentre was determined.

7. Whether or not the earthquake is known to have been felt.

8. A reference to any work in which special attention was devoted to that earthquake.

Data are added to the file as they come to hand. At the time of preparing this note, the earliest earthquake on the file is one that occurred about the year 1460 , and the most recent shocks are those of the year 1974. Sources for various periods are as follows :-

$1460-1854$

Definitive catalogues of New Zealand earthquakes for this period have been published, based on all available historical and archival material. Fiby, G. A., 1968. A Descriptive Catalogue of New Zealand Earthquakes. Part 1. Shocks Felt Before the End of 1845. N.Z.J. Geol. Geophys. 11, 16-40. Eiby, G. A., 1973. A Descriptive Catalogue of New Zealand Earthquakes. Part 2. Shocks felt from 1846-1854. N.Z.J. Geol. Geophys. 16, 857-907.

1855-1939

Earthquakes in this period have not been fully studied, but a provisional list of major earthquakes has been published.

* Seismological Observatory, Geophysics Division, DSIR, Wellington, New Zealand.
Eiby, G. A., 1968. An Annotated List of New Zealand Earthquakes, 1460-1965. N.Z. J. Geol. Geophys. 11, 630-647.

Early shocks are documented by felt data alone, but instrumental readings are available to assist locations from 1900, with increasingly good coverage from 1930. The file for this period contains those earthquakes in the Annotated Iist, supplemented in a few cases from other sources. These earthquakes total only 115 , and will be supplemented when historical studies are more complete.

1940-1942

Origins are listed in Seismological Observatory Bulletins E94-105. Some unpublished revisions have been made available by Mr. G. A. Eiby.

1943-1954

Origins have been taken from original notes kept by Seismological observatory staff members.

1955-1963

Graphically determined origins, listed in Seismological Observatory Bulletins E136-144, have been used.

1964-1974

Origins determined by computer, listed in Seismological Observatory Bulletins E145-155, have been used. Earthquakes for the year 1970, some stili awaiting analysis, have yet to be added.

Access to the file is provided by a computer programme, which enables a set of search criteria to be specified. These criteria may be any combination of the following:-

1. Date of occurrence. Shocks that occurred between two specified dates may be chosen.

2. Epicentre. Three types of search are available:

(a) latitude and longitude limits may be specified;

(b) a circular region may be defined;

(c) a convex polygonal area of up to nine sides may be specified.

3. Focal depth. Minimum and maximum depths (e.g. 0 to $50 \mathrm{~km}$ ) may be specified.

4. Magnitude. A certain magnitude range may be requested. Richter's local magnitude scale is used, although for much of the early data magnitudes are given alphabetic classification. These may also be specified as search parameters. 
5. Quality of solution. Since 1964, when the observatory began to use a computer for routine epicentre determinations, the standard error of the arrival time residuals at the observing stations has been calculated. This, with the number of recording stations and the number of seismic phases observed, is a measure of the reliability of the solution. For shocks that occurred before 1964, the accuracy is specified as an alphabetic class, A, B, C, or D.

6. Solution code. Particular codes may be selected.

7. Felt information. Earthquakes that have been reported felt may be selected.

The observatory is prepared to make appropriate listings available to geologists, engineers and others for research purposes. In view of the obvious dangers that can arise from incomplete assessments of earthquake risk, users are asked to discuss their search criteria and the limitations of the data with the Observatory. Requests should be addressed to The Superintendent, Seismological observatory, Geophysics Division, Department of Scientific and Industrial Research, Box 1320, Wellington.

\section{ACKNOWLEDGEMENTS}

I am indebted to Mr. G. A. Eiby for making available certain unpublished material and for his advice and suggestions at all stages. 